\title{
Kinetic Analysis of the Thermal Decomposition of Latex Foam according to Thermogravimetric Analysis
}

\author{
Hongwei Fan, ${ }^{1,2}$ Yongliang Chen, ${ }^{2,3}$ Dongmei Huang, ${ }^{2,3}$ and Guoqin Wang1,2 \\ ${ }^{1}$ Zhejiang Furniture and Hardware Research Institute, Hangzhou, Zhejiang 310018, China \\ ${ }^{2}$ Key Laboratory of Furniture Inspection Technology of Zhejiang Province, Hangzhou, Zhejiang 310018, China \\ ${ }^{3}$ College of Quality and Safety Engineering, China Jiliang University, Hangzhou, Zhejiang 310018, China
}

Correspondence should be addressed to Dongmei Huang; 20021567@163.com

Received 7 October 2016; Accepted 23 November 2016

Academic Editor: Hossein Roghani-Mamaqani

Copyright (C) 2016 Hongwei Fan et al. This is an open access article distributed under the Creative Commons Attribution License, which permits unrestricted use, distribution, and reproduction in any medium, provided the original work is properly cited.

\begin{abstract}
The thermal decomposition of latex foam was investigated under nonisothermal conditions. Pieces of commercial mattress samples were subjected to thermogravimetric analysis (TG) over a heating range from $5^{\circ} \mathrm{C} \mathrm{min}^{-1}$ to $20^{\circ} \mathrm{C} \mathrm{min}^{-1}$. The morphology of the latex foam before and after combustion was observed by scanning electron microscopy (SEM), and the primary chemical composition was investigated via infrared spectroscopy (FT-IR). The kinetic mechanism and relevant parameters were calculated. Results indicate that the decomposition of latex foam in the three major degradation phases is controlled by third-order reaction (F3) and by Zhuravlev's diffusion equation (D5). The mean $E$ values of each phase as calculated according to a single heating rate nonisothermal method are equal to $41.91 \pm 0.06 \mathrm{~kJ} \mathrm{~mol}^{-1}, 86.32 \pm 1.04 \mathrm{~kJ} \mathrm{~mol}^{-1}$, and $19.53 \pm 0.11 \mathrm{~kJ} \mathrm{~mol}^{-1}$, respectively. Correspondingly, the preexponential factors of each phase are equal to $300.39 \mathrm{~s}^{-1}, 2355.65 \mathrm{~s}^{-1}$, and $27.90 \mathrm{~s}^{-1}$, respectively. The mean activation energy $E$ and preexponential factor $A$ of latex foam estimated according to multiple heating rates and a nonisothermal method are $92.82 \mathrm{~kJ} \mathrm{~mol}^{-1}$ and $1.12 \times 10^{-3} \mathrm{~s}^{-1}$, respectively.
\end{abstract}

\section{Introduction}

Latex foam is an elastic, light weight and flexible form of latex with tremendous economic importance. It is used extensively in automobiles, home ware, airplanes, and so on. It is generally known that latex foam is a cellular structure comprised of liquid latex compounds [1-3]. The structural characteristics indicate that latex foam has a high potential fire risk, and decomposition is one of the major fire behaviors exhibited by foam materials. Thermogravimetric analysis (TGA) is a useful technique to investigate decomposition processes of materials and their related kinetics [4-6]. The results of TG analysis are useful for the study of combustion mechanisms.

The thermal decomposition of natural rubber latex and investigation of its primary chemical component, styrenebutadiene block copolymer, has been the subject of much previous research and received considerable research [7]. Hacaloglu et al. [8] reported that the degradation yield of styrene-butadiene-styrene copolymer reaches a maximum at $213^{\circ} \mathrm{C}$. Other researchers have investigated the thermal behavior of natural rubber latex blends [9-11]. Results indicate that blending improves the thermal stability of the mixture. For instance, the activation energy of chitosan (CS)/natural rubber latex (NRL) composites falls in the range of $30 \mathrm{~kJ} \mathrm{~mol}^{-1}-60 \mathrm{~kJ} \mathrm{~mol}^{-1}$. The various structures of styrenebutadiene block copolymers have also been studied [12] Their activation energy falls in the range of $100 \mathrm{~kJ} \mathrm{~mol}^{-1}$ $300 \mathrm{~kJ} \mathrm{~mol}^{-1}$, and their thermal degradation includes three stages: gas, degradation wax, and residue. The endothermic peak occurs at approximately $450^{\circ} \mathrm{C}$.

Previous studies have detailed the thermal degradation of the materials which are used to form latex foam. However, the materials used in commercial products are typically mixtures of several materials. The decomposition process and the related kinetics will vary greatly from that of pure materials or mixtures comprised of only two components. The latex foam widely used in bedding is typically the primary source of room fires. Unfortunately, very little is 
known about the decomposition processes and the kinetic combustion mechanism of latex foam used in commercial products. Reported research regarding the chemical reaction mechanism of latex foam is particularly scarce. Consequently, further investigation of the thermal degradation behavior of latex foam is necessary.

The objectives of this study are to present an experimental description of the thermal behavior, the pyrolytic process, and the kinetic mechanism of latex foam in a heating rate range of $5^{\circ} \mathrm{C} / \mathrm{min}$ to $20^{\circ} \mathrm{C} / \mathrm{m}$ in according to thermogravimetric analysis (TGA). The morphology of latex foam before and after combustion was observed by scanning electron microscopy (SEM). The primary chemical composition of the samples was characterized via infrared spectroscopy (FTIR). The activation energy $(E)$ values and the preexponential factors $(A)$ of the thermal reaction were studied according to nonisothermal methods (with both single and multiple heating rates). The reaction mechanism functions of various thermal degradation phases were also investigated.

\section{Experimental Procedure}

The samples used in this work consist of commercially available latex foam used in mattresses (Sleemon Furniture Co., Ltd., China). The materials were first cut into blocks of dimensions $5 \mathrm{~mm} \times 5 \mathrm{~mm} \times 5 \mathrm{~mm}$; measurements were then taken from these blocks. The primary chemical composition of the samples was characterized by FT-IR analysis, Nicolet iS10.

The structure of samples of dimensions $2 \mathrm{~mm} \times 2 \mathrm{~mm}$ $\times 2 \mathrm{~mm}$ was observed by SEM, Tesla BS 340 . The thermal degradation process and its related kinematics were investigated by TG analysis (SDT Q600, TA Instruments) with a heating rate ranging from room temperature to $800^{\circ} \mathrm{C}$. The heating rate $(\theta)$ varied from $5^{\circ} \mathrm{C} / \mathrm{min}$ to $20^{\circ} \mathrm{C} \mathrm{min}^{-1}$ under a constant air flow $\left(100 \mathrm{~cm}^{3} \mathrm{~min}^{-1}\right)$. The initial sample weight was approximately equal to $10 \mathrm{mg}$. The precision of results was improved by determining average testing values from two replications of each experiment.

The kinetic parameters were extracted based on the degree of conversion $(\alpha)$ as follows [13]:

$$
\alpha=\frac{m_{0}-m_{t}}{m_{0}-m_{\infty}}
$$

where $m_{0}, m_{t}$, and $m_{\infty}$ represent the initial sample mass, the sample mass at time $t$, and the sample mass at the conclusion of the experiment.

\section{Results and Discussion}

First, the morphology of the latex foam before and after combustion was observed by SEM at accelerating voltages in the range of $15 \mathrm{kv}-35 \mathrm{kv}$. SEM images of the latex foam are depicted in Figure 1. As shown in Figure 1, the studied latex foam is a three-dimensional porous polymer, in which the interconnected pores are of a size $>200 \mu \mathrm{m}$ and demonstrate a wall thickness of approximately $20 \mu \mathrm{m}$, as shown in Figure 1(a). Generally, three-dimensional porous organic

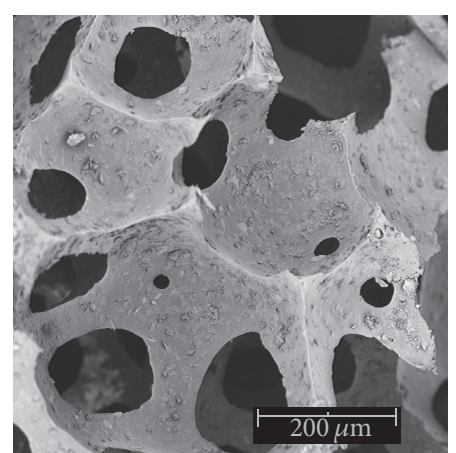

(a)

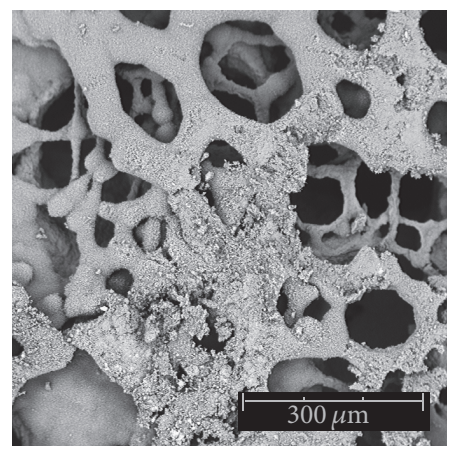

(b)

FIgURE 1: Scanning electron micrograph of latex foam, (a) before and (b) after combustion.

polymers are very easy to ignite, and the subsequent flame spreads extremely quickly. Therefore, latex foam poses a great fire hazard. After combustion, the morphology of the latex foam was also three-dimensional and porous, which is as it was prior to combustion and as is shown in Figure 1(b). A very smooth frame work surface is also observed, which appears to represent a liquid cooling formation. This may be a result of the thermal decomposition of synthetic polymers, which typically pass through an oil/wax phase [14].

The most probable chemical composition of the latex foam was then determined by FT-IR. The infrared spectrum of latex foam is presented in Figure 2. The functional group monosubstituted aromatic hydrocarbons at $701 \mathrm{~cm}^{-1}$, $1496 \mathrm{~cm}^{-1}, 1605 \mathrm{~cm}^{-1}$, and $3033 \mathrm{~cm}^{-1}$ and aliphatic hydrocarbons at $868 \mathrm{~cm}^{-1}, 1451 \mathrm{~cm}^{-1}$, and $2915 \mathrm{~cm}^{-1}$ were observed for the sample. The match degree between the infrared spectra of latex foam and the styrene-butadiene block copolymer is greater than $80 \%$. Thus, it can be induced that the primary chemical components of the latex foam used in the present experiment were styrene-butadiene block copolymer [15-17]. Styrene-butadiene block copolymer usually contains approximately $75 \%$ styrene and $25 \%$ butadiene and is a relatively easy flow material [18]. The related chemical formula is depicted in Figure 3. An easy flow material will flow easily when the temperature rises to a certain value. The rubber will begin to crosslink, and the ease of flow will decrease as the temperature continues to rise past an optimal value. This corresponds with the results observed by SEM. 


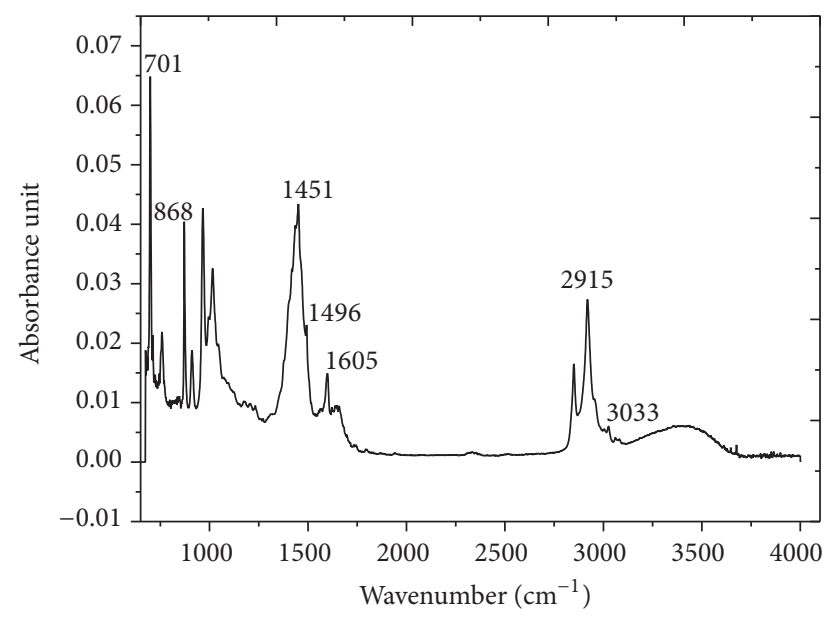

Figure 2: Baseline-corrected infrared spectrum of latex foam.

$$
\begin{gathered}
\left(\mathrm{CH}_{2}-\underset{\mid}{\mathrm{CH}}\right)_{n}-\left(\mathrm{CH}_{2}-\mathrm{CH}=\mathrm{CH}-\mathrm{CH}_{2}\right)_{n}+\left(\mathrm{CH}_{2}-\mathrm{CH}\right)_{n} \\
\mathrm{CH}=\mathrm{CH}_{2}
\end{gathered}
$$$$
\text { 1,2 Butadiene } \quad 1,4 \text { Butadiene }(\mathrm{C} \text { and } \mathrm{T}) \quad \text { Styrene }(\mathrm{S})
$$

FIGURE 3: The structure of the styrene-butadiene block copolymer [12].

3.1. Pyrolytic Analysis. A typical TG plot representing the latex foam at a heating rate of $10^{\circ} \mathrm{Cmin}^{-1}$ is shown in Figure 4 . The first decomposition phase should correspond to water evaporation, which occurs from the initial temperature up to approximately $140^{\circ} \mathrm{C}$. The mass loss during this phase is approximately equal to $0.5 \mathrm{wt} \%$. The subsequent phase which occurs from $250^{\circ} \mathrm{C}$ to $420^{\circ} \mathrm{C}$ should consist of the pyrolysis of latex foam which produces various volatile and char (phase II). The mass loss which occurs during this phase is approximately equal to $40 \%$. Next, the expressive decomposition peak at $440^{\circ} \mathrm{C}$ belongs to the oil/wax producing phase. The sample mass was reduced by approximately $20 \mathrm{wt} \%$ during this process (phase III). Phases II and III indicate the thermal decomposition of the styrene-butadiene block copolymer [8]. Based on these results, the estimated styrene-butadiene block copolymer content is approximately $60 \mathrm{wt} \%$. This is in good agreement with the results observed by FT-IR. The subsequent decomposition peak that occurs at approximately $680^{\circ} \mathrm{C}$ is related to the gas formation phase (phase IV). At the conclusion of phase IV, the mass is approximately $25 \mathrm{wt} . \%$.

The thermodecomposition curves of various heating rates are shown in Figure 5. The temperature range and conversion degree of each composition phase at different heating rates are listed in Table 1. Results demonstrate that the decomposition phase is shifted to a higher temperature. The temperature range of phase II increases, while that of phase three decreases as the heating rate increases from $5^{\circ} \mathrm{C} \mathrm{min}{ }^{-1}$ to $20^{\circ} \mathrm{C} \mathrm{min}^{-1}$. The shape of the TG and DTG curve is nearly identical under the various heating rate conditions. This indicates that the kinetic mechanism of the material is not altered as a result

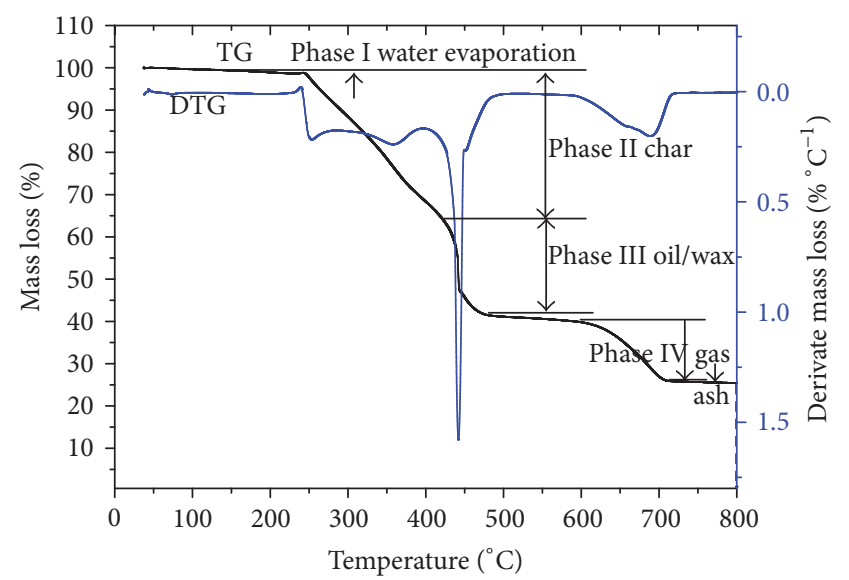

FIGURE 4: Decomposition curve for latex foam with heating rate of $10^{\circ} \mathrm{C} \mathrm{min}^{-1}$.

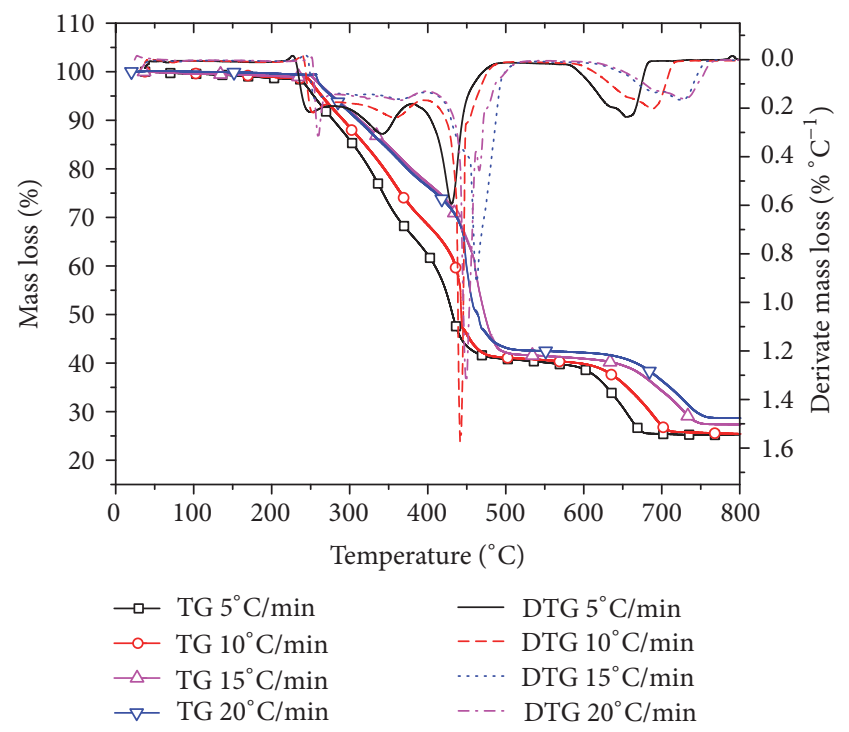

Figure 5: Thermal decomposition of latex foam.

of heating rate, as the shape of the TG curve is determined by the kinetic mechanism function.

3.2. Kinetics of Thermal Degradation. The kinetics of the thermal degradation of latex foam and the reaction kinetic parameters $E$ and $k$ were investigated according to nonisoconversional methods.

3.2.1. Single Rate Isothermal Method. The relationship developed by Petr Ptáček et al. [19] was employed, as follows:

$$
\ln \left[\frac{g(y)}{T^{2}}\right] \cong \ln \left(\frac{A R}{\theta E}\right)-\frac{E}{R T},
$$

where $E$ is the activation energy, $\mathrm{kJ} \mathrm{mol}^{-1} ; R$ is the universal gas constant, $8.314 \mathrm{~J} \cdot \mathrm{mol}^{-1} \cdot \mathrm{K}^{-1} ; T$ is the temperature, $\mathrm{K} ; A$ is the preexponential factor; $\theta$ is the heating rate, $\mathrm{K} \mathrm{min}^{-1}$; and the function $g(y)$ represents the kinetic function. $E$ and $A$ are temperature independent parameters. The probable 
TABLE 1: The summary of pyrolysis characteristic temperatures at the heating rate from 5 to $20^{\circ} \mathrm{C} \mathrm{min}^{-1}$.

\begin{tabular}{cccccccccc}
\hline$\theta\left({ }^{\circ} \mathrm{C} / \mathrm{min}\right)$ & Phase & $\Delta T\left({ }^{\circ} \mathrm{C}\right)$ & $T_{\max }\left({ }^{\circ} \mathrm{C}\right)$ & $\alpha$ & $\theta\left({ }^{\circ} \mathrm{C} / \mathrm{min}\right)$ & Phase & $\Delta T\left({ }^{\circ} \mathrm{C}\right)$ & $T_{\max }\left({ }^{\circ} \mathrm{C}\right)$ & $\alpha$ \\
\hline \multirow{4}{*}{5} & I & -231.8 & 231.8 & -0.016 & & I & -244.71 & 244.71 & -0.014 \\
& II & $253.79-380.17$ & 340.50 & $0.066-0.452$ & \multirow{2}{*}{10} & II & $245.48-395.85$ & 323.89 & $0.018-0.41$ \\
& III & $380.17-492.71$ & 430.90 & $0.452-0.79$ & & III & $395.85-513.00$ & 441.97 & $0.41-0.79$ \\
& IV & $582.19-686.43$ & 655.99 & $0.81-1.0$ & & IV & $574.81-719.80$ & 683.66 & $0.80-1$ \\
\hline \multirow{4}{*}{15} & I & -254.73 & 254.73 & -0.014 & & I & -261.71 & 261.71 & -0.023 \\
& II & $251.94-402.13$ & 381.77 & $0.015-0.32$ & \multirow{2}{*}{20} & II & $264.86-401.38$ & 365.41 & $0.045-0.32$ \\
& III & $402.13-525.92$ & 462.27 & $0.32-0.80$ & & III & $393.52-519.39$ & 451.18 & $0.32-0.81$ \\
& IV & $638.46-758.38$ & 725.18 & $0.80-1$ & & IV & $623.94-769.44$ & 733.09 & $0.81-1$ \\
\hline
\end{tabular}

TABLE 2: Kinetic model functions $g(\alpha)$ usually employed for reactions.

\begin{tabular}{lccccc}
\hline Number & Function name & Formula of $g(y)$ & Number & Function name & Formula of $g(y)$ \\
\hline 1 & One-third order (F1/3) & $1-(1-y)^{2 / 3}$ & 15 & Parabolic law D1 & $y^{2}$ \\
2 & Three-quarters order (F3/4) & $1-(1-y)^{1 / 4}$ & 16 & Valensi eq. D2 & $y+(1-y) \ln (1-y)$ \\
3 & One-and-a-half-order F3/2 & $(1-y)^{-1 / 2}-1$ & 17 & Jander eq. D3 & {$\left[1-(1-y)^{1 / 3}\right]^{2}$} \\
4 & Second-order F2 & $(1-y)^{-1}-1$ & 18 & Ginstling-Brounstein eq. D4 & $1-(2 y / 3)-(1-y)^{2 / 3}$ \\
5 & Third-order F3 & $(1-y)^{-2}-1$ & 19 & Zhuravlev eq. D5 & {$\left[(1-y)^{-1 / 3}-1\right]^{2}$} \\
6 & Mampel power law P1/2 & $y^{1 / 2}$ & 20 & Anti-Jander eq. D6 & {$\left[(1+y)^{1 / 3}-1\right]^{2}$} \\
7 & Avrami-Erofeev eq. F1 & $-\ln (1-y)$ & 21 & Anti-Ginstling-Brounstein eq. D7 & $1+(2 y / 3)-(1+y)^{2 / 3}$ \\
8 & Avrami-Erofeev eq. A3/2 & {$[-\ln (1-y)]^{2 / 3}$} & 22 & Anti-Zhuravlev eq. D8 & {$\left[(1+y)^{-1 / 3}-1\right]^{2}$} \\
9 & Avrami-Erofeev eq. A2 & {$[-\ln (1-y)]^{1 / 2}$} & 23 & G4 & {$[-\ln (1-y)]^{2}$} \\
10 & Avrami-Erofeev eq. A3 & {$[-\ln (1-y)]^{1 / 3}$} & 24 & G5 & {$[-\ln (1-y)]^{3}$} \\
11 & Avrami-Erofeev eq. A4 & {$[-\ln (1-y)]^{1 / 4}$} & 25 & G6 & {$[-\ln (1-y)]^{4}$} \\
12 & Power law R1 & $y$ & 26 & G7 & {$\left[1-(1-y)^{1 / 2}\right]^{1 / 2}$} \\
13 & Power law R2 & $1-(1-y)^{1 / 2}$ & 27 & & {$\left[1-(1-y)^{1 / 3}\right]^{1 / 2}$} \\
14 & Power law R3 & $1-(1-y)^{1 / 3}$ & & & \\
\hline
\end{tabular}

mechanism was substituted into (2) in order to calculate $\ln \left[g(y) / T^{2}\right]$. Then, $\ln \left[g(y) / T^{2}\right]$ versus $\left(T^{-1}\right)$ was plotted. The correlation coefficient was obtained by means of the linear fitting method. The most consistent kinetic function was determined based on the correlation coefficient, which should approach 1. $E$ and $A$ were estimated from the slope and intercept of the linear equation.

The most probable kinetic mechanism of the thermal decomposition reaction for phases II-IV of pyrolysis was determined. The kinetic degree of conversion $\alpha$ for each phase was employed to determine that the most probable mechanism was $0.1-0.3,0.4-0.7$, and $0.85-0.95$, respectively. The most likely kinetic mechanism of the thermal degradation reaction was assessed using 27 mathematical functions reported in previous work [20-22]. The proposed functions can be classified into four types: chemical, nucleation, boundary, and diffusion reactions, as shown in Table 2. Figure 6 depicts the phase II results as an example.

The correlation coefficient of the linear regression representing the third-order chemical reaction (F3) and Zhuravlev's diffusion equation (D5) for phases II, III, and IV is very near to 1 , indicating that a three-mechanism kinetic function is the most probably reaction mechanism.

The activation energy $E$ and preexponential factor $A$ can be graphically estimated from the straight line representing $\ln \left[g(y) / T^{2}\right]$ versus $T^{-1}$. The results for each decomposition phase are depicted in Table 3. The mean $E$ values of each phase are $41.91 \pm 0.06 \mathrm{~kJ} \mathrm{~mol}^{-1}, 86.32 \pm 1.04 \mathrm{~kJ} \mathrm{~mol}^{-1}$, and $19.53 \pm$ $0.11 \mathrm{~kJ} \mathrm{~mol}^{-1}$, respectively, and the respective preexponential factors are equal to $300.39 \mathrm{~s}^{-1}, 2355.65 \mathrm{~s}^{-1}$, and $27.90 \mathrm{~s}^{-1}$. Munteanu et al. [12] reported that the activation energies of butadiene styrene copolymers with different architectures fall in the range $100 \mathrm{~kJ} \mathrm{~mol}^{-1}-300 \mathrm{~kJ} \mathrm{~mol}^{-1}$. Rao and Johns [9] indicated that the activation energy of chitosan (CS)/natural rubber latex (NRL) blends falls in the range of $30 \mathrm{~kJ} \mathrm{~mol}^{-1}$ $60 \mathrm{~kJ} \mathrm{~mol}^{-1}$. Some researchers $[10,11]$ have concluded that the blending of materials improves the thermal stability of the overall mixture. Experimental results are in good agreement with those reported above.

3.2.2. Multiple Rate Nonisothermal Method. The Flynn-Wall (FWO) expression was used to evaluate the $E$ and $A$ values of the thermal decomposition of latex foam $[23,24]$ :

$$
\ln \left[\frac{\alpha}{T^{2}}\right]=\ln \left(\frac{A R}{E}\right)+0.6075-\frac{E}{R T} .
$$

In order to obtain $E$, a linear relationship between $\ln \left(\alpha / T^{2}\right)$ and $T^{-1}$ at selected fractions of the thermal decomposition is plotted as shown in Figure 7 , and $E$ is then evaluated from the related slopes. 
TABLE 3: Kinetic parameters within different conversion range.

\begin{tabular}{ccccccc}
\hline$\theta\left[{ }^{\circ} \mathrm{C} \mathrm{m^{-1 } ]}\right.$ & $y$ & $g(y)$ & Slope & Intercept & $E\left[\mathrm{~kJ} \mathrm{~mol}^{-1}\right]$ & $A\left[\mathrm{~s}^{-1}\right]$ \\
\hline \multirow{4}{*}{5} & Phase II & F3 & $-5746.85 \pm 4.38$ & $-3.33223 \pm 0.01$ & $47.78 \pm 0.04$ & $1.03 \times 10^{3}$ \\
& Phase III & D5 & $-4276.61 \pm 21.18$ & $-10.381 \pm 0.031$ & $35.56 \pm 0.18$ & $6.63 \times 10^{-1}$ \\
& Phase IV & D5 & $-3002.44 \pm 25.08$ & $-10.5595 \pm 0.03$ & $24.96 \pm 0.21$ & $3.90 \times 10^{-1}$ \\
\hline \multirow{4}{*}{10} & Phase II & F3 & $-5287.49 \pm 6.42$ & $-4.40778 \pm 0.01$ & $43.96 \pm 0.05$ & $6.44 \times 10^{2}$ \\
& Phase III & D5 & $-5023.23 \pm 75.06$ & $-9.65617 \pm 0.11$ & $41.76 \pm 0.62$ & $3.22 \times 10^{0}$ \\
& Phase IV & D5 & $-2529.98 \pm 8.77$ & $-11.2159 \pm 0.01$ & $21.03 \pm 0.07$ & $3.40 \times 10^{-1}$ \\
\hline \multirow{4}{*}{15} & Phase II & F3 & $-4436.54 \pm 7.81$ & $-6.2424 \pm 0.01$ & $36.89 \pm 0.06$ & $1.29 \times 10^{2}$ \\
& Phase III & D5 & $-12479.00 \pm 105.18$ & $4.71395 \pm 0.18$ & $103.75 \pm 0.87$ & $2.09 \times 10^{7}$ \\
& Phase IV & D5 & $-1876.00 \pm 7.22$ & $-12.0302 \pm 0.01$ & $15.60 \pm 0.06$ & $1.68 \times 10^{-1}$ \\
\hline \multirow{2}{*}{20} & Phase II & F3 & $-4692.34 \pm 11.31$ & $-5.74382 \pm 0.02$ & $39.01 \pm 0.09$ & $3.01 \times 10^{2}$ \\
& Phase III & D5 & $-19751.30 \pm 297.20$ & $21.51204 \pm 0.571$ & $164.21 \pm 2.47$ & $8.69 \times 10^{14}$ \\
& Phase IV & D5 & $-1985.40 \pm 10.98$ & $-11.9449 \pm 0.01$ & $16.51 \pm 0.09$ & $2.58 \times 10^{-1}$ \\
\hline
\end{tabular}

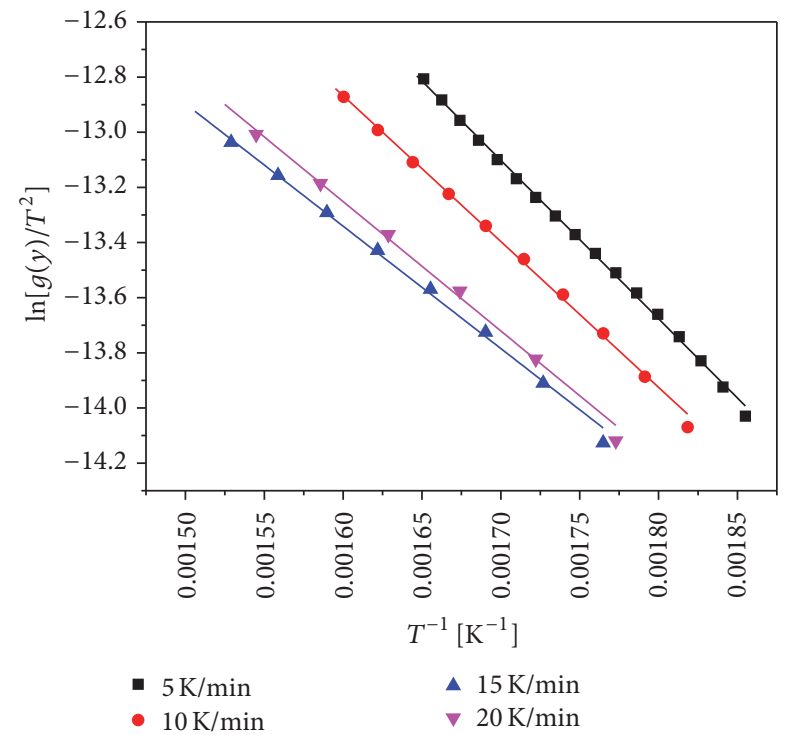

Figure 6: The $\ln \left[g(y) / T^{2}\right]$ versus $T^{-1}$ of different heating rate in phase II.

As described above, the application of the multiple rate nonisothermal method requires determination of the absolute temperature at which a fixed extent of combustion was observed based on the thermoanalytical curves recorded at various heating rates. Calculation of the kinetic parameters focused on the dominant reaction only, in which the conversion degree ranged from 0.1 to $0.3,0.4$ to 0.7 , and 0.85 to 0.95 . When $\ln \left(\alpha / T^{2}\right)$ versus $T^{-1}$ was plotted at identical degrees of conversion, a set of straight lines was obtained for the material (Figure 7). Thus, the activation energy for a certain extent of conversion could be obtained based on the slopes of the resulting lines. The related values of $E$ and $A$ for each fraction are depicted in Table 4. It was observed that the activation energy varied very little with the extent of conversion, with a mean value of $92.824 \mathrm{~kJ} \mathrm{~mol}^{-1}$.

The average activation energy of each conversion phase is $72.09 \mathrm{~kJ} \mathrm{~mol}^{-1}, 140.70 \mathrm{~kJ} \mathrm{~mol}^{-1}$, and $89.62 \mathrm{~kJ} \mathrm{~mol}^{-1}$, respectively. Experimental values were greater than those calculated

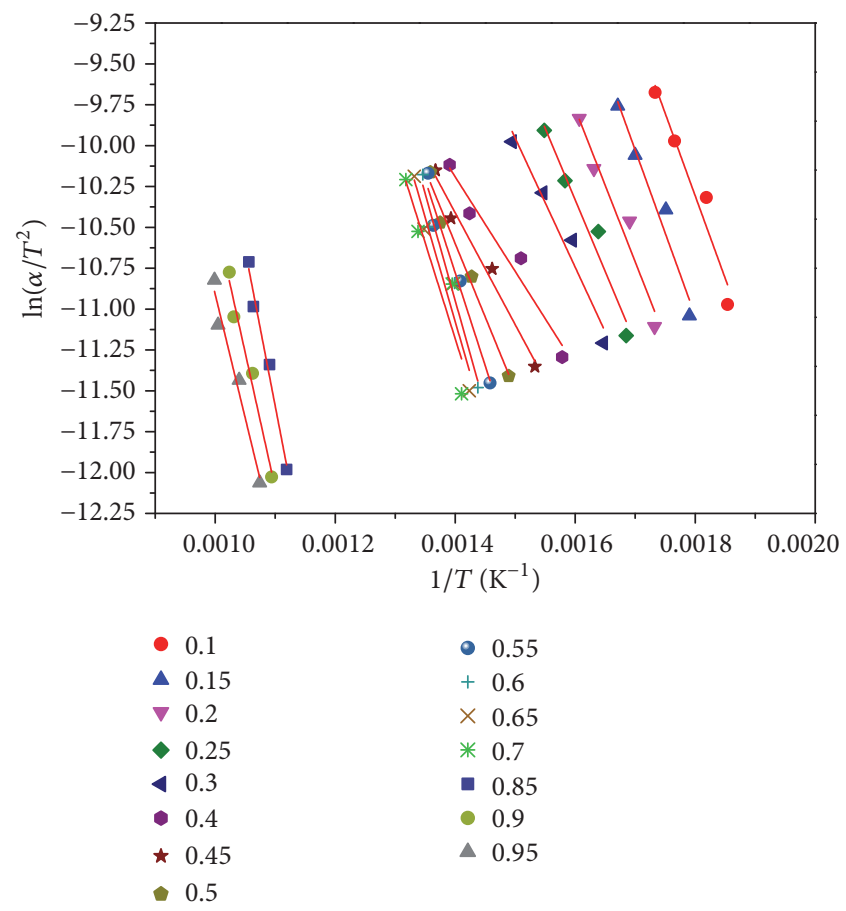

Figure 7: Arrhenius plot of $\ln \left(\alpha / T^{2}\right)$ versus $T^{-1}$ at selected conversion degree.

according to the single rate nonisothermal method representing the same conversion phase. However, experimental and calculated results demonstrate identical change trends, in which the average activation energy in the conversion phase of $0.4-0.7$ is greater than that observed in the other two phases. This corresponds with the pyrolysis process depicted in Figure 4.

\section{Conclusion}

The degradation kinetics of commercial latex foam were investigated according to TG. Both the single and multiple rate nonisothermal methods were applied to determine the 
TABLE 4: Kinetic parameters under nonisothermal condition within different conversion range.

\begin{tabular}{|c|c|c|c|c|c|}
\hline$\alpha$ & Slope & Intercept & $R$ & $E\left[\mathrm{~kJ} \mathrm{~mol}^{-1}\right]$ & $A\left[\times 10^{-5} \mathrm{~s}^{-1}\right]$ \\
\hline 0.1 & 7.86039 & -10093.2 & 0.92357 & 83.92 & 142.5344 \\
\hline 0.15 & 7.22801 & -10150.3 & 0.94245 & 84.39 & 76.1603 \\
\hline 0.2 & 5.19057 & -9353.86 & 0.93251 & 77.77 & 9.1494 \\
\hline 0.25 & 3.66033 & -8745.82 & 0.94817 & 72.71 & 1.8519 \\
\hline 0.3 & 1.895 & -7899.47 & 0.94635 & 65.68 & 0.2863 \\
\hline 0.4 & -2.09521 & -5782.91 & 0.93739 & 48.08 & 0.0039 \\
\hline 0.45 & -0.83763 & -6838.39 & 0.97089 & 56.85 & 0.0161 \\
\hline 0.5 & 1.96565 & -8975.1 & 0.97294 & 74.62 & 0.3490 \\
\hline 0.55 & 5.13672 & -11367.8 & 0.95453 & 94.51 & 10.5363 \\
\hline 0.6 & 7.33653 & -13060.7 & 0.95381 & 108.59 & 109.2312 \\
\hline 0.65 & 6.7196 & -12711.5 & 0.89676 & 105.68 & 57.3653 \\
\hline 0.7 & 5.23099 & -11723 & 0.79906 & 97.47 & 11.9398 \\
\hline 0.85 & 9.36043 & -19048.7 & 0.97518 & 158.37 & 1205.6289 \\
\hline 0.9 & 6.16507 & -16602 & 0.9688 & 138.03 & 43.0311 \\
\hline 0.95 & 4.20772 & -15117.9 & 0.95648 & 125.69 & 5.5341 \\
\hline
\end{tabular}

activation energy $E$ and the preexponential factor $A$ in the primary decomposition phases. The single rate nonisothermal method combined with 27 mathematical functions reported in previous research was used to define the most suitable reaction mechanism $g(\alpha)$. It can be concluded that the pyrolysis process is comprised of four discontinuous regions. The average activation energy of phases II-IV is $41.91 \pm 0.06 \mathrm{~kJ} \mathrm{~mol}^{-1}, 86.32 \pm 1.04 \mathrm{~kJ} \mathrm{~mol}^{-1}$, and $19.53 \pm$ $0.11 \mathrm{~kJ} \mathrm{~mol}^{-1}$, respectively, and the respective preexponential factors are $300.39 \mathrm{~s}^{-1}, 2355.65 \mathrm{~s}^{-1}$, and $27.90 \mathrm{~s}^{-1}$. Correspondingly, the most probable mechanism functions for phases IIIV are a third-order reaction $\left((1-y)^{-2}-1\right)$, Zhuravlev's diffusion equation $\left(\left[(1-y)^{-1 / 3}-1\right]^{2}\right)$, and Zhuravlev's diffusion equation $\left(\left[(1-y)^{-1 / 3}-1\right]^{2}\right)$, respectively. The mean activation energy of each respective phase is $72.09 \mathrm{~kJ} \mathrm{~mol}^{-1}$, $140.70 \mathrm{~kJ} \mathrm{~mol}^{-1}$, and $89.62 \mathrm{~kJ} \mathrm{~mol}^{-1}$ according to calculated kinematic parameters determined by the multiple rate nonisothermal method.

\section{Competing Interests}

The authors declare that they have no competing interests.

\section{Acknowledgments}

This work was supported by the National Natural Science Foundation of China, no. 51306168, and Zhejiang Provincial Natural Science Foundation of China under Grant no. LY17E060004, and the Key Laboratory of Furniture Inspection Technology of Zhejiang Province, no. 2016J08.

\section{References}

[1] N. Board, Handbook on Rubber and Allied Products (with Project Profiles), Niir Project Consyltancy Service, 2013.

[2] D. Eaves, Handbook of Polymer Foams, RAPRA Limited, Telford, UK, 2004.
[3] R. Roslim, M. Y. Amir Hashim, and P. T. Augurio, "Natural latex foam," Journal of Engineering Science, vol. 8, pp. 15-27, 2012.

[4] P. Ptáček, D. Kubátová, J. Havlica, J. Brandštetr, F. Šoukal, and T. Opravil, "Isothermal kinetic analysis of the thermal decomposition of kaolinite: The Thermogravimetric Study," Thermochimica Acta, vol. 501, no. 1-2, pp. 24-29, 2010.

[5] H. Jiang, J. Wang, S. Wu, B. Wang, and Z. Wang, "Pyrolysis kinetics of phenol-formaldehyde resin by non-isothermal thermogravimetry," Carbon, vol. 48, no. 2, pp. 352-358, 2010.

[6] H. Geßwein and J. R. Binder, "Thermokinetic study of the oxidation of $\mathrm{ZrAl}_{3}$ powders," Thermochimica Acta, vol. 444, no. 1, pp. 6-12, 2006.

[7] J. Xu, A. Zhang, T. Zhou, X. Cao, and Z. Xie, "A study on thermal oxidation mechanism of styrene-butadiene-styrene block copolymer (SBS)," Polymer Degradation and Stability, vol. 92, no. 9, pp. 1682-1691, 2007.

[8] J. Hacaloglu, T. Ersen, N. Ertugrul, M. M. Fares, and S. Suzer, "Pyrolysis mass spectrometric analysis of styrene-butadiene block and random copolymers," European Polymer Journal, vol. 33, no. 2, pp. 199-203, 1997.

[9] V. Rao and J. Johns, "Thermal behavior of chitosan/natural rubber latex blends TG and DSC analysis," Journal of Thermal Analysis and Calorimetry, vol. 92, no. 3, pp. 801-806, 2008.

[10] A. P. Mathew, S. Packirisamy, and S. Thomas, "Studies on the thermal stability of natural rubber/polystyrene interpenetrating polymer networks: thermogravimetric analysis," Polymer Degradation and Stability, vol. 72, no. 3, pp. 423-439, 2001.

[11] J. T. Varkey, S. Augustine, and S. Thomas, “Thermal degradation of natural rubber/styrene butadiene rubber latex blends by thermogravimetric method," Polymer-Plastics Technology and Engineering, vol. 39, no. 3, pp. 415-435, 2000.

[12] S. B. Munteanu, M. Brebu, and C. Vasile, "Thermal and thermo-oxidative behaviour of butadiene-styrene copolymers with different architectures," Polymer Degradation and Stability, vol. 89, no. 3, pp. 501-512, 2005.

[13] C. Oh and C. M. Sorensen, "The effect of overlap between monomers on the determination of fractal cluster morphology," Journal of Colloid and Interface Science, vol. 193, no. 1, pp. 17-25, 1997. 
[14] J. M. Encinar and J. F. González, "Pyrolysis of synthetic polymers and plastic wastes. Kinetic study," Fuel Processing Technology, vol. 89, no. 7, pp. 678-686, 2008.

[15] J. Madejová, "FTIR techniques in clay mineral studies," Vibrational Spectroscopy, vol. 31, no. 1, pp. 1-10, 2003.

[16] F. Boccuzzi, A. Chiorino, M. Manzoli et al., "Au/TiO2 nanosized samples: a catalytic, TEM, and FTIR study of the effect of calcination temperature on the CO oxidation," Journal of Catalysis, vol. 202, no. 2, pp. 256-267, 2001.

[17] R. P. Singh, S. M. Desai, S. S. Solanky, and P. N. Thanki, "Photodegradation and stabilization of styrene-butadiene-styrene rubber," Journal of Applied Polymer Science, vol. 75, no. 9, pp. 1103-1114, 2000.

[18] T. Whelan and J. Goff, "Styrene butadiene block copolymer," in Injection Molding of Thermoplastics Materials-1, pp. 100-110, Springer US, Boston, Mass, USA, 1990.

[19] P. Ptáček, F. Šoukal, T. Opravil, J. Havlica, and J. Brandštetr, “The kinetic analysis of the thermal decomposition of kaolinite by DTG technique," Powder Technology, vol. 208, no. 1, pp. 20-25, 2011.

[20] R. López-Fonseca, I. Landa, U. Elizundia, M. A. GutiérrezOrtiz, and J. R. González-Velasco, "Thermokinetic modeling of the combustion of carbonaceous particulate matter," Combustion and Flame, vol. 144, no. 1-2, pp. 398-406, 2006.

[21] P. Ptáček, D. Kubátová, J. Havlica, J. Brandštetr, F. Šoukal, and T. Opravil, "The non-isothermal kinetic analysis of the thermal decomposition of kaolinite by thermogravimetric analysis," Powder Technology, vol. 204, no. 2-3, pp. 222-227, 2010.

[22] Y. Han, T. Li, and K. Saito, "Comprehensive method based on model free method and IKP method for evaluating kinetic parameters of solid state reactions," Journal of Computational Chemistry, vol. 33, no. 31, pp. 2516-2525, 2012.

[23] Y.-K. Lee, D.-J. Kim, H.-J. Kim, T.-S. Hwang, M. Rafailovich, and J. Sokolov, "Activation energy and curing behavior of resol- and novolac-type phenolic resins by differential scanning calorimetry and thermogravimetric analysis," Journal of Applied Polymer Science, vol. 89, no. 10, pp. 2589-2596, 2003.

[24] D. Huang, X. Wang, and J. Yang, "Influence of particle size and heating rate on decomposition of bc dry chemical fire extinguishing powders," Particulate Science and Technology, vol. 33, no. 5, pp. 488-493, 2015. 

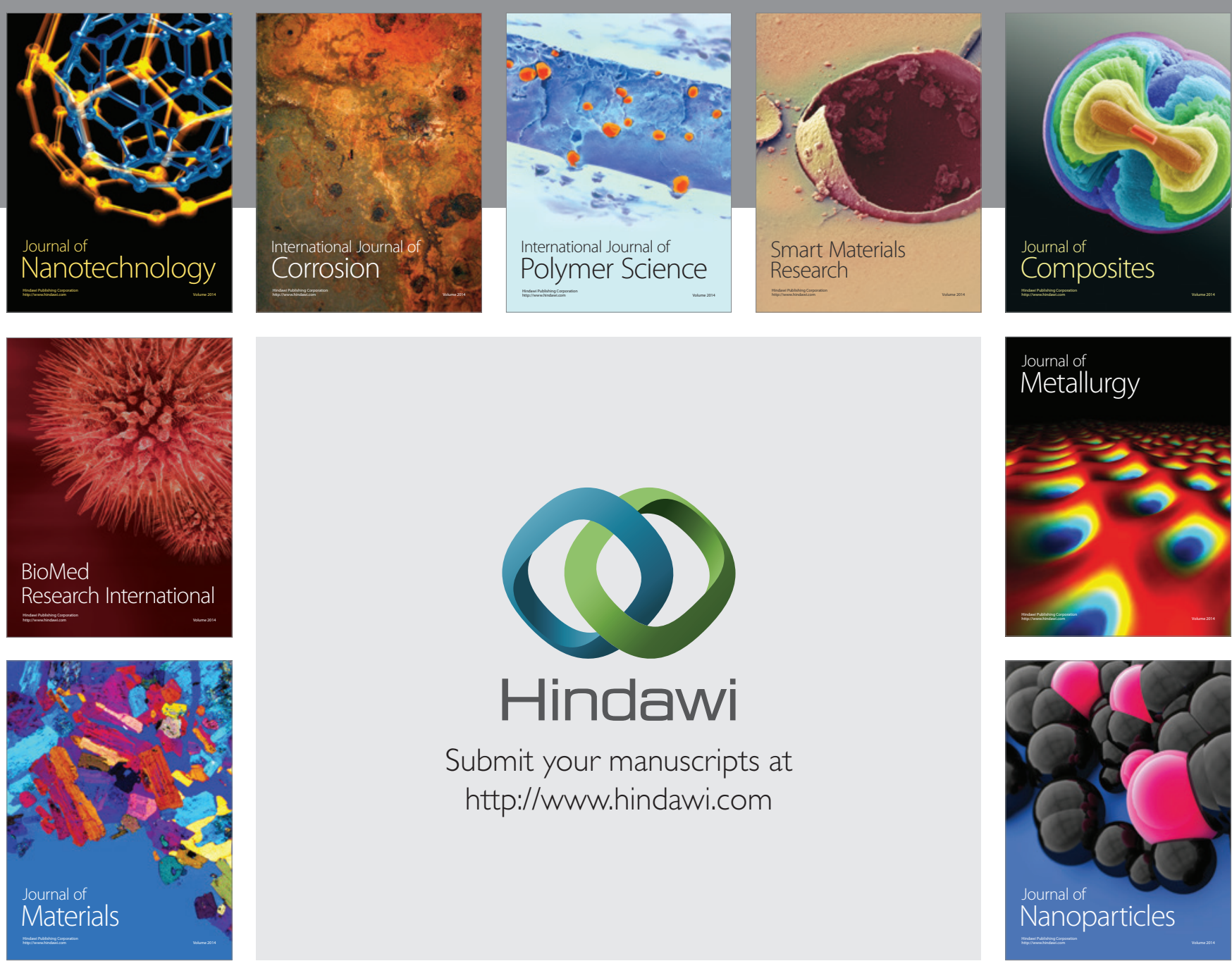

\section{Hindawi}

Submit your manuscripts at

http://www.hindawi.com

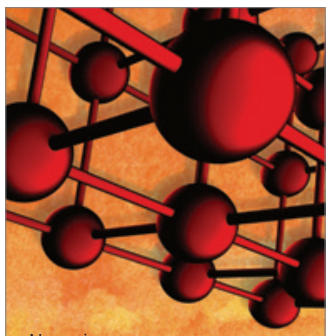

Materials Science and Engineering
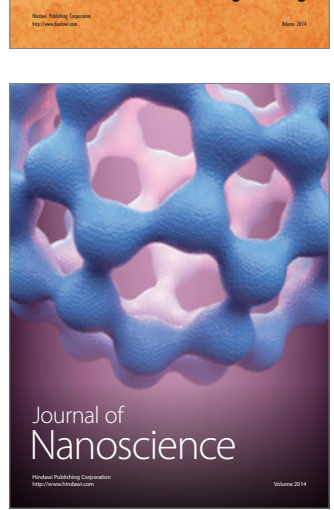
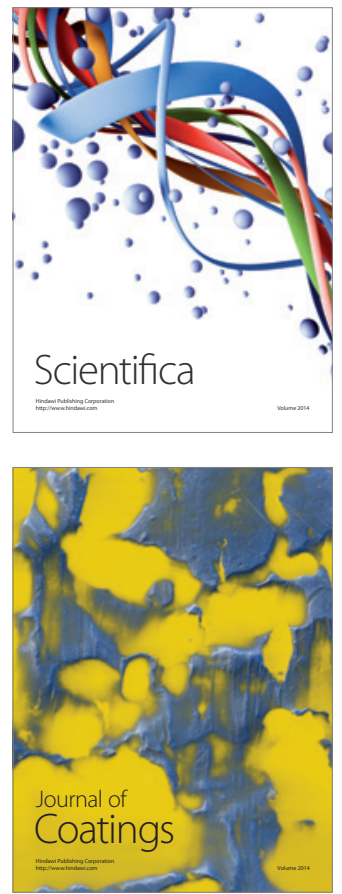
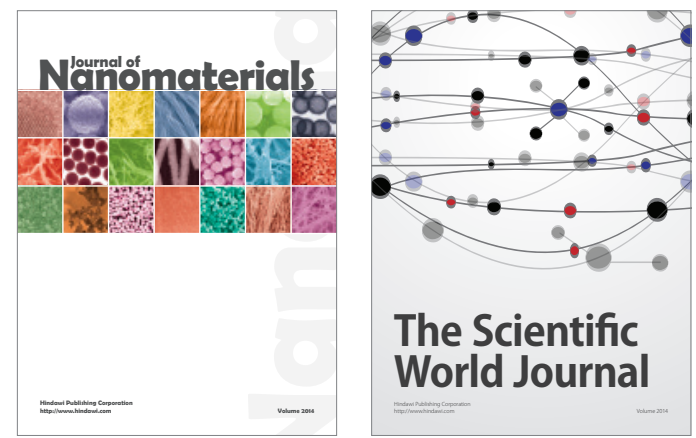

The Scientific World Journal
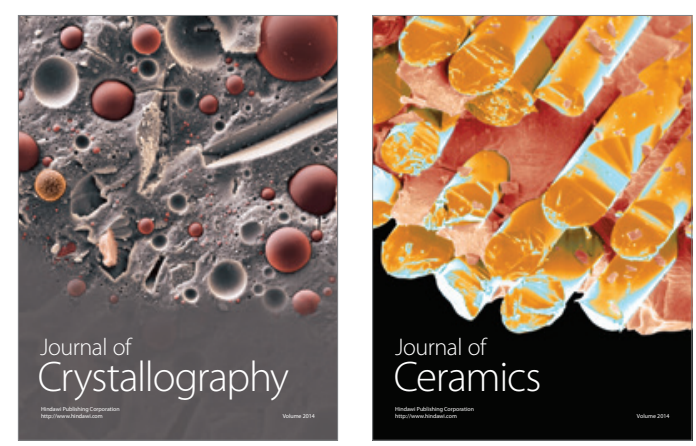
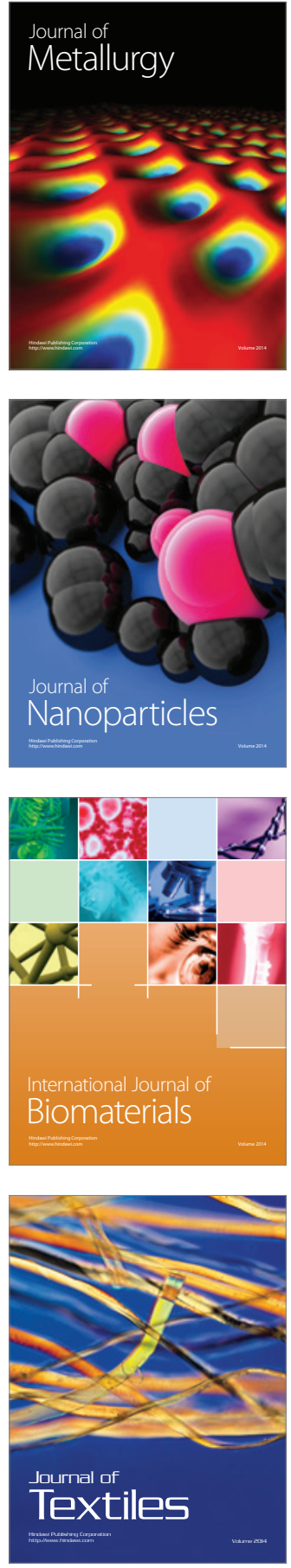